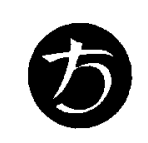

Tusculum-Bücherei

Herausgeber: Karl Bayer, Max Faltner, Gerhard Jäger 



\title{
LIBANIOS Briefe
}

\author{
Griechisch - deutsch
}

\author{
In Auswahl \\ herausgegeben, übersetzt und erläutert \\ von \\ G. Fatouros und T.Krischer
}

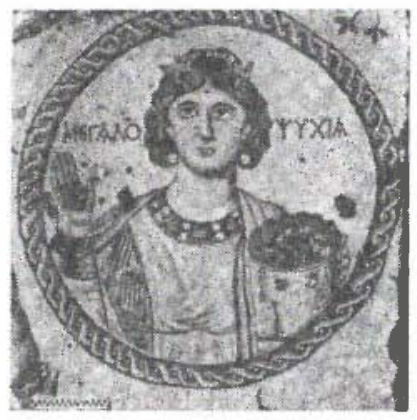

HEIMERAN VERLAG MÜNCHEN 
Titelvignette:

Megalopsychia, „Großherzigkeit",

Mosaik aus Antiochia,

Heimat und Wirkungsstätte des Libanios

CIP-Kurztitelaufnahme der Deutschen Bibliothek

Libanius: [Sammlung] Briefe / Libanios.

Hrsg. u. übers. von G.Fatouros u. T. Krischer. -

München: Heimeran, 1979.

(Tusculum-Bücherei) ISBN 3-7765-2186-4

München 1980

(C) Heimeran Verlag

Alle Rechte vorbehalten, einschließlich die der fotomechanischen Wiedergabe Satz und Druck: Laupp \& Göbel, Tübingen Bindung: Heinr. Koch, Tübingen Archiv 637 ISBN 3-7765-21 86-4 